\title{
Evaluation of the effectiveness of selected natural fertility symptoms used for contraception: estimation of the Pearl index of Lady-Comp, Pearly and Daysy cycle computers based on 10 years of observation in the Polish market
}

\author{
Aleksandra Demiańczyk, Krzysztof Michaluk
}

B-CSp.j.

\begin{abstract}
Objectives: Cycle computers are medical devices which use sophisticated statistical methods in addition to a comprehensive on-board database. Their main function is to precisely indicate the fertile and infertile phases of the menstrual cycle, based on daily basal body temperature measurements. A recent medical research program aimed at evaluating the EFFECTIVENESS of cycle computers for contraceptive purposes was conducted.

Material and methods: This study was conducted between May and June 2016 on 3,450 Polish women. The Polish distributor sent an anonymous questionnaire to the participants. To date, 361 women, representing 17,322 cycles have returned accurately completed questionnaires.

Results: In the resultant group only 4 unintended pregnancies were observed, resulting in a Pearl index of 0.4989 . This suggests that fewer than 5 in 1000 women, who use a cycle computer correctly over a period of one year, may become pregnant unintentionally. This result is slightly better than the results from 2010, when the Pearl index was 0.64.

Conclusions: The results obtained from the study indicate that the effectiveness of cycle computers for contraceptive purposes is comparable with other methods, such as hormonal contraception, and therefore cycle computers can be recommended for women who either cannot use or do not wish to use traditional contraception. These results confirm the effectiveness of using natural fertility symptoms, such as basal body temperature changes in the context of cycle computer technology for the purposes of contraception.
\end{abstract}

Key words: pearl index, contraception, symptom-thermal method, cycle computer

Ginekologia Polska 2016; 87, 12: 793-797

\section{INTRODUCTION}

The use of natural symptoms, such as basal body temperature variations, for the determination of phases of the menstrual cycle is an area of research interest. In particular, the application of these measurements for the purposes of contraception remains a known research problem. To date, standard methods used to relate natural symptoms to menstrual cycle phases have been encumbered by human and measurement errors. Only the introduction of cycle computers has led to developments in this field, as these devices measure and analyze body temperature automati- cally, thereby eliminating subjective assessment error, as well as improving capabilities for data analysis. With these devices, it is possible to answer the question whether or not natural fertility symptoms, such as basal body temperature, can be used for contraceptive purposes. The Pearl index, which is an indicator of contraceptive method effectiveness, was used to assess the efficacy of cycle computers in the present study.

The present study attempts to evaluate the effectiveness of the application of natural fertility symptoms (thermal method) for contraceptive purposes. Specifically, the main 
aim of this research was to evaluate cycle computers, including the Lady-Comp models [1], based on estimation of the Pearl index for this method, a means of quantifying the efficacy of a contraceptive method.

An additional objective of this study was the evaluation of the effectiveness of predicting the child's sex in couples using Baby-Comp or Lady-Comp cycle computers, when used for conception planning.

\section{MATERIAL AND METHODS}

This study aims to evaluate whether it is possible to use a natural fertility symptom, such as basal body temperature changes, for effective contraception.

Cycle computers function based on the thermal method, where basal body temperature is measured (at rest and immediately after waking up). These devices have a temperature sensor built-in and temperature is recorded and analyzed routinely over time. Unlike other methods, that are classified as "natural", cycle computers use quantitative data (temperature), which can be used for modelling with mathematical and statistical methods. Temperature measurement [2] is a precise, objective evaluation not susceptible to human error, because the entire process is performed by the device, unlike in other natural methods, such as those that use the extensibility of cervical mucus as a key parameter. The evaluation of the extensibility of cervical mucus is subjective and therefore it is prone to inter-observer variations and cannot be relied upon for objective analysis. Introduction of qualitative parameters to statistical methods has a negative impact on the predictive ability of the technique. The Lady-Comp, Pearly and Daysy cycle computers were used to explore the efficacy of using natural fertility symptoms for contraceptive purposes, as these devices work only on quantitative data and a statistical model based on this data, thus preventing human error. It is possible to explore this possibility by estimating the percentage of planned pregnancies in women using this medical device for contraception. The patients included in the study did not use other forms of contraception except for cycle diagnostics using a cycle computer. The Lady-Comp computer is a medical diagnostic tool, which determines fertility phases, and the final effect depends on the user's intention. Therefore, these devices may also be used to facilitate conception, based on optimal timing of sexual intercourse relative to the phase of the menstrual cycle.

A detailed description of the methods used to obtain data was presented in a similar study in 2010 [3]. However, this study group has been significantly extended in the present study, because of access to the larger database of Lady-Comp cycle computer users. The study was conducted between May and June, 2016. In this period 3,450 surveys were sent to eligible participants. As of the end of June,
2016, 361 completed surveys had been returned. Each of the women surveyed used the cycle computer for at least 12 months. The basic group of respondents was randomly chosen from the entire database of the Polish distributor of VE Valley Electronics $\mathrm{GmbH}$ and accounted for $50 \%$ of the population in the database.

The characteristics of cycle computer function is presented in previous published literature [4]. However, to date there are 5 cycle computers on the market: Lady-Comp, Lady-Comp Basic, Lady-Comp Baby, Daysy and Pearly. All models differ in shape and built-in features but all have the same software for analyzing fertile and infertile days. Additionally, each model is equipped with a temperature sensor.

The method used for Pearl index estimation in cycle computers was based on assumptions presented by R. Pearl in 1933 [5]. In order to make the results of the present study comparable to the study from 2010 [3] a similar method was used, including the survey design and statistical methods.

The survey did not substantially differ from the one used in the previous study [3]. However, the most recent survey has an additional question (six in total) relating to the usage of cycle computers in forecasting the sex of the child. The Lady-Comp Baby and Baby-Comp cycle computers have such function and their algorithm is based on the manufacturer's own studies. Question 6 was presented as follows:

6. Have you used Baby-Comp or Lady-comp Baby for baby sex prognosis?

- Yes, (if yes, please answer question 6.1.).

- No.

6.1. Did the cycle computer properly indicate baby sex?

- Yes,

- No.

This question enabled identification of the number of patients who use the cycle computer for contraception in a manner consistent with manufacturer instructions (e.g. always follow the indications of the cycle computer and never have unprotected sex in the fertile phase), but became pregnant regardless. Using this method allows for calculation of the Pearl index, specific to the use of cycle computers for contraception purposes.

\section{RESULTS}

Within the study, 361 completed surveys were received as of $30 / 06 / 2016$, comprising $10.46 \%$ of all sent questionnaires. A statistical summary of responses to particular questions is presented in Tables 1-9.

The following comments should be noted for the answers to these questions:

- in question 1, only two respondents used the Daysy cycle computer. This model was introduced on the market in Poland recently at the beginning of 2015, and therefore the number of users is low; 


\begin{tabular}{|l|c|c|c|c|}
\hline Table 1. Question 1 answer structure \\
\hline Cycle computer & Total & Structure & Total* $^{*}$ & Structure* \\
\hline Pearly & 136 & $37.67 \%$ & 126 & $40.00 \%$ \\
\hline Daysy & 2 & $0.55 \%$ & 1 & $0.32 \%$ \\
\hline Lady-Comp & 142 & $39,34 \%$ & 121 & $38.41 \%$ \\
\hline Baby-Comp & 48 & $13.30 \%$ & 45 & $14.29 \%$ \\
\hline Lady-Comp Basic & 26 & $7.20 \%$ & 16 & $5.08 \%$ \\
\hline Lady-Comp Baby & 7 & $1.94 \%$ & 6 & $1.90 \%$ \\
\hline
\end{tabular}

*Devices used for more than 12 months

Table 2. Question 2 answer structure

\begin{tabular}{|l|l|}
\hline Parameter & Value \\
\hline Arithmetic average & 53.69 \\
\hline Standard deviation & 30.20 \\
\hline Median & 50.00 \\
\hline Dominant & 52.00 \\
\hline
\end{tabular}

Table 3. Question 3 answer structure

\begin{tabular}{|l|c|c|}
\hline Question 3 & Answer YES & Answer NO \\
\hline Number of answers & 94 & 221 \\
\hline Structure & $29.84 \%$ & $70.16 \%$ \\
\hline
\end{tabular}

Table 4. Question 3.1 answer structure (in case of answer YES to question 3)

\begin{tabular}{|l|c|c|}
\hline Question 3 & Answer YES & Answer NO \\
\hline Number & 21 & 73 \\
\hline Structure & $22.34 \%$ & $77.66 \%$ \\
\hline
\end{tabular}

Table 5. Question 3.2 answer structure (in case of answer YES to question 3)

\begin{tabular}{|l|c|c|}
\hline Question 3.2 & Number & Structure \\
\hline Condom & 77 & $81.91 \%$ \\
\hline Coitus interruptus & 5 & $5.32 \%$ \\
\hline Observation of mucus & 5 & $5.32 \%$ \\
\hline Creighton model & 2 & $2.13 \%$ \\
\hline Pill & 1 & $1.06 \%$ \\
\hline Thermometer & 1 & $1.06 \%$ \\
\hline Contraceptive inserts & 1 & $1.06 \%$ \\
\hline Ovulation test & 1 & $1.06 \%$ \\
\hline NaProTechnology & 1 & $1.06 \%$ \\
\hline Total & 94 & $100 \%$ \\
\hline
\end{tabular}

\begin{tabular}{|l|c|c|}
\hline \multicolumn{3}{|l|}{ Table 6. Question 4 answer structure } \\
\hline Question 4 & Answer YES & Answer NO \\
\hline Number & 271 & 44 \\
\hline Structure & $86.03 \%$ & $13.97 \%$ \\
\hline
\end{tabular}

\begin{tabular}{|l|c|c|}
\hline Table 7. Question $\mathbf{5}$ answer structure \\
\hline Question 5 & Answer YES & Answer NO \\
\hline Number & 17 & 298 \\
\hline Structure & $5.40 \%$ & $94.60 \%$ \\
\hline
\end{tabular}

Table 8. Question 6 answer structure (in case of answer "Baby-Comp" and "Lady-Comp Baby" in question 1)

\begin{tabular}{|l|c|c|}
\hline Question 6 & Answer YES & Answer NO \\
\hline Number & 28 & 24 \\
\hline Structure & $53.85 \%$ & $46.15 \%$ \\
\hline
\end{tabular}

Table 9. Question 6.1 answer structure (in case of answer YES

to question 6)

\begin{tabular}{|l|c|c|}
\hline Question 6.1 & Answer YES & Answer NO \\
\hline Number & 20 & 8 \\
\hline Structure & $71.43 \%$ & $28.57 \%$ \\
\hline
\end{tabular}

- in question 2, regarding the duration of computer usage, the arithmetic average amounted to 50 cycles (distribution was close to normal), which satisfies the requirements for a sufficient cycle number for an assessment of cycle computer efficacy;

- in question 2 , some users $(n=46)$ answered that they have been using a cycle computer for less than 12 months and these surveys were not used for further analysis;

- in question 3, regarding other contraception methods, 221 users answered that a computer is the only method used for cycle diagnostics, which means that this group did not have sex in the fertile phase. Only if the respondent answered YES to this question, was the survey was used for further analysis;

- in question $4,13.97 \%$ of users declared that they do not always follow the indications of the computer; these surveys were not used for further analysis;

- in question 5, 17 users answered that they got pregnant despite using the cycle computer device. However, 13 of them answered "NO" for question 4.; these surveys were not used to estimate the Pearl index;

- question 6 and 6.1 refer to usage of Baby-Comp and Lady Comp for prediction of the child's sex. 28 women (53.85\%) used these computers to predict the child's 
sex, and in $71.43 \%$ the device predicted the sex of the unborn child correctly.

\section{DISCUSSION}

The Pearl index was estimated using the method described in reference [4], thus assuming 13 menstrual cycles per year. Calculation of base values, which constituted input data for the Pearl's formula required a logical algorithm meeting all of the following criteria:

- usage of the cycle computer for 13 cycles or more,

- no other forms of contraception,

- strictly following the indications of the cycle computer. In this way, the total number of cycles evaluated in the study was assessed. The number of pregnancies in this group constituted the second component for calculation. The detailed algorithm used for estimation of the Pearl index based on obtained data is presented on Figure 1.
As a result, the Pearl index was estimated at 0.4989. The effectiveness of Lady-Comp, Pearly, and Daysy cycle computers expressed as a percentage amounted to $95.5 \%$. Therefore, it can be concluded that the effectiveness of this medical device based on a natural fertility symptoms such as basal body temperature is high and comparable with other known contraception methods [6-8]. Assuming perfect usage of this method, the effectiveness of avoiding conception may be high, when only the cycle computer is used. Cycle computers operate based on the algorithmic fertility diagnostic tool that uses quantitative data such as body temperature measurements. It is possible that elimination of human error in the course of fertility phase diagnostics and decision making regarding fertility was facilitated by cycle computer use, leading to the observed low error rate associated with the method (with error estimated at $0.5 \%$ ). This software was created based on a database consist-

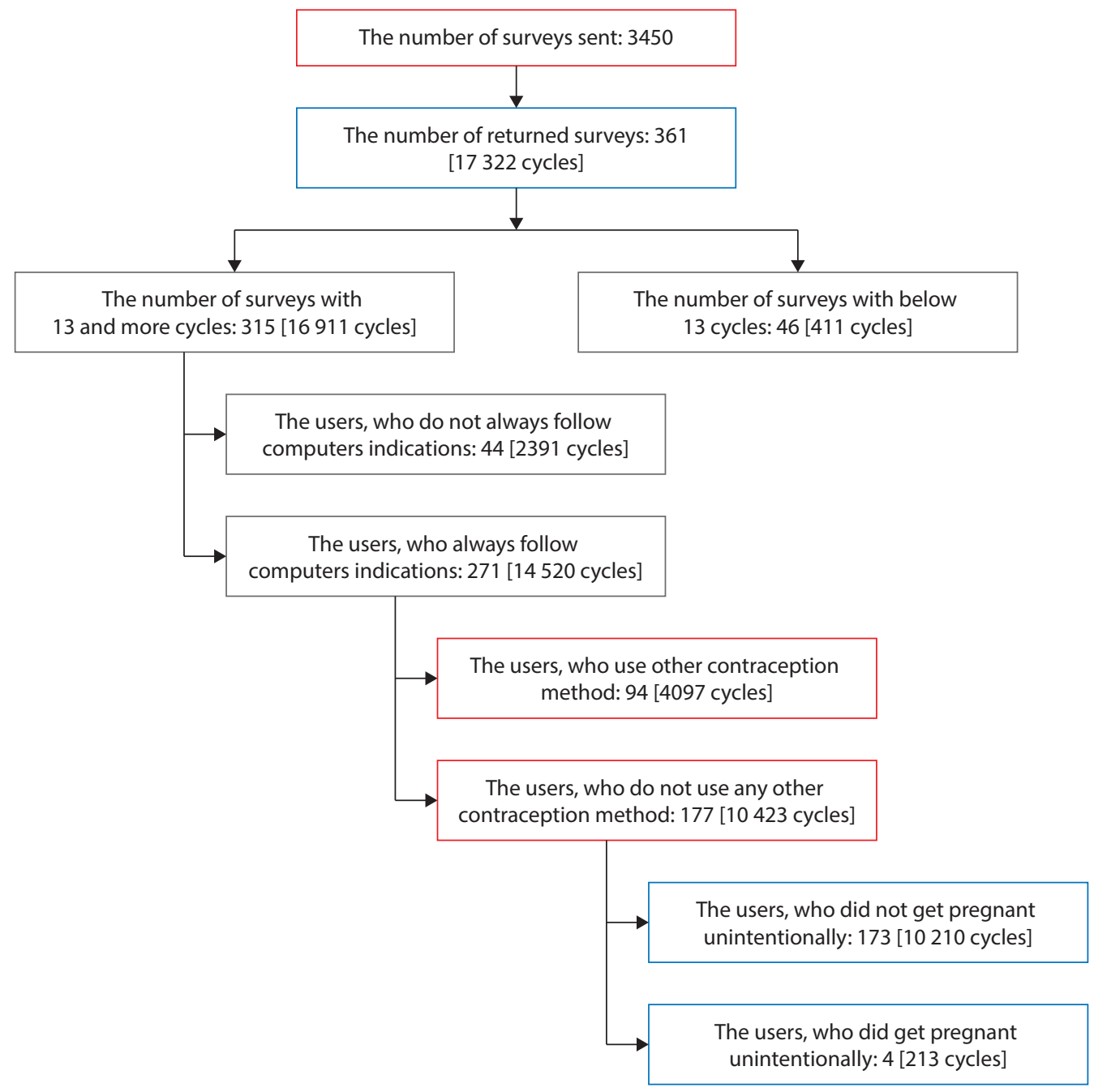

Figure 1. The algorithm estimating the number of cycles involved in calculation of the Pearl Index 
ing of a 'validation group', which included over a million cycles. Furthermore, the software is able to adapt and generalize the information acquired about characteristics of the body temperature changes in the particular user. In contrast to the previous studies $[3,9]$, the results of the present stud suggest that the effectiveness of cycle computers has increased in this population. The Pearl index obtained was comparable to other such devices [10]. This improvement can be explained by refinement of the algorithms used by cycle computers for fertility diagnostics as well as a significantly larger study group.

In addition to the Pearl index calculation, this survey also shows the effectiveness of two models (Baby-comp and Lady-comp Baby) of cycle computers in sex prognosis. 51 respondents declared they were using Baby-Comp or Lady-comp Baby (new model), with 28 people using it for sex prognosis. In 20 cases out of 28 (71.43\%) the cycle computer correctly indicated the sex of the baby. This value shows the effectiveness of cycle computers for sex prognosis when the user plans conception based on intercourse in the fertile phase indicated by the device. 8 respondents out of $28(28.57 \%)$ gave a negative answer, suggesting that the method was not perfect.

\section{CONCLUSIONS}

The hypothesis stated at the beginning of this study regarding possible application of a natural fertility symptoms, such as basal temperature changes, was confirmed. The efficacy estimated for cycle computers chosen for this trial (Lady-Comp, Pearly, and Daysy) proved that these devices are able to identify the fertility phases accurately, and therefore may be used for contraception. The error rate of $0.5 \%$ with perfect usage is comparable with other methods of contraception. It was also proven that it is possible to predict the sex of the baby with an efficacy of $71.43 \%$ using some models of the devices (Baby-Comp and Lady-Comp Baby only).

\section{REFERENCES}

1. Stanowisko Zespołu Ekspertów Polskiego Towarzystwa Ginekologicznego w zakresie wykorzystania Naturalnych Metod Planowania Rodziny do celów antykoncepcyjnych. Ginekol Pol. 2010, 12, 947.

2. Świadectwo wzorcowania Laboratorium Pomiarowe OPTEL, Numer świadectwa: 20160809.01, Szczecin 2016/08/09.

3. Binkiewicz P, Michaluk K, Demiańczyk A. Indeks Pearly komputerów cykl Lady-Comp, Baby-Comp i Pearly stosowanych jako metoda antykoncepcji. Ginekol Pol. 2010, 11, 834-839.

4. Meisenbacher K. Komputery Lady-Comp i i Baby-Comp . [In]: Petryński T, Zyss T. (eds.). Antykoncepcja. Metody. Zastosowanie. Poradnictwo. It $^{\text {st }}$ ed. Polish. Med Pharm. 2008, 167-168.

5. Pearl R. Factors in human fertility and their statistical evaluation. Lancet. 1933, 222, 607-611.

6. Rekomendacje Polskiego Towarzystwa Ginekologicznego w sprawie antykoncepcji. Ginekologia po Dyplomie. 2008, 233-235.

7. Word Heath Organization. Family planning/Contraception. Fact sheet N³51. May 2015.

8. Pawelczyk L, Banaszewska B. Regulacja urodzin. [In]: Bręborowicz G.H. (ed.). Ginekologia i Położnictwo. PZWL, Warszawa 2005, 953-955.

9. Freundl FH, Godehardt E, Klemm R, Bachhofer M. Trial of contraceptive effectiveness of LADY-COMP /BABY-COMP. Advances in Contraception 1998, 14, 97-108.

10. Walczak K. Nowoczesne technologie. Płodność. Materiały konferencyjne „Profilaktyka zdrowia prokreacyjnego" pt. „Wokół ludzkiej prokreacji - odkrycia i nowości. Rozpoznawanie płodności, diagnostyka i leczenie zaburzeń" 10/2014. Warszawski Uniwersytet Medyczny. 